\title{
Impact of education family support behaviors on adherence to the drug patients with Myocardial Infarction
}

\author{
$\underline{\text { Mojgan Mokhtari Tabas }}{ }^{1}$ (D), Tooba Kazemi' ${ }^{2}$ (D), Farah Madarshahian ${ }^{3}$ \\ ${ }^{1}$ Corresponding author; Student Research Committee, Birjand University of Medical Sciences, Birjand, Iran \\ ${ }^{2}$ Cardiovascular Research Center, Birjand University of Medical Sciences, Birjand, Iran \\ ${ }^{3}$ Faculty of Nursing and Midwifery, Birjand University of Medical Sciences, Birjand, Iran
} Tel: +5632328424_E-mail:mojgan.mokhtari1365@gmail.com

Citation Mokhtari Tabas M, Kazemi T, Madarshahian F. [Impact of education family support behaviors on
adherence to the drug patients with Myocardial Infarction]. J Birjand Univ Med Sci. 2019; 26(2): 98-105.
[Persian]
DOI http://doi.org/10.32592/JBirjandUnivMedSci.2019.26.2.101
Received: September 19,2018 Accepted: February 20, 2019

\begin{abstract}
Background and Aim: Failure to follow the drug is common in patients with myocardial infarction. However, it has been reported in various studies that family support can improve adherence to drug in chronic diseases. The purpose of this study was to investigation the impact of education of family support behaviors on adherence to the drug in patients with myocardial infarction.

Materials and Methods: This controlled clinical trial study was performed on 70 patients with myocardial infarction, which had criteria for entering the study. Patients were randomly divided into intervention and control groups and demographic information and adherence to the drug was completed questionnaire for two groups. Individuals who received inadequate the drug follow-up based on this questionnaire were completed their family support questionnaire. In order to intervene, in the form of at least three educational sessions, based on the needs assessment of the two previous questionnaires, training was provided to the key member of the intervention group family and three months after the intervention, the two drug and family support questionnaires were re-completed for the two groups. Finally, the data was entered into SPSS software (version 16). Descriptive statistics including frequency, mean, standard deviation for description and description of data and analytical statistics including: Chi-square, paired T-test and independent $\mathrm{T}$-test were used for data analysis. The significance level was considered as $(\mathrm{P}<0.05$. $)$
\end{abstract}

Results: The mean score of family supportive behaviors and adherence to the drug in the intervention group was significantly higher than the control group after the intervention $(\mathrm{P}<0.001)$. Also, the mean of changes in drug follow-up $(\mathrm{P}<0.001)$ and family support $(\mathrm{P}<0.001)$ after intervention in the intervention group were significantly higher than the control group.

Conclusion: The teaching of family supportive behaviors can improve the adherence to the drug in patients with myocardial infarction.

Keywords: Myocardial Infarction; Adherence to drug Therapy; Family Support 


\section{تأثير آموزش رفتار هاى حمايتى خانواده بر \\ ييروى دارويى مبتلايان به انفار كتوس ميوكارد}

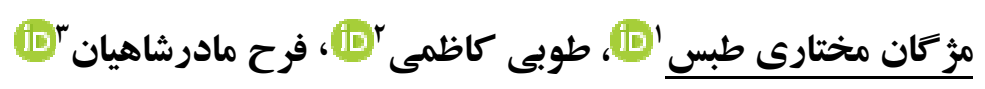

جـكيله

زمينه و هدف: عدم ييروى دارويى در بيماران با انفاركتوس ميوكارد شايع است. اين در حالى است كه در مطالعات مختلف گزارش

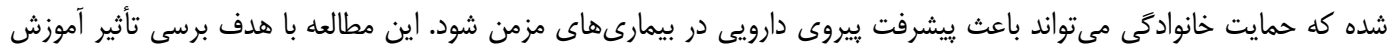

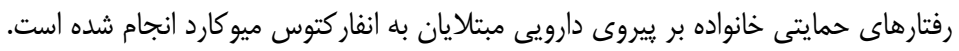

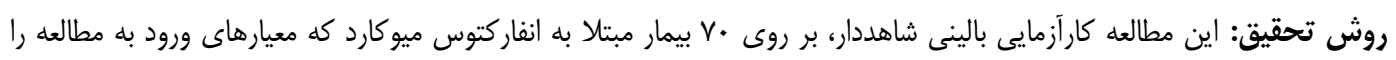

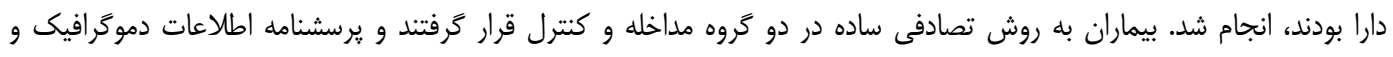

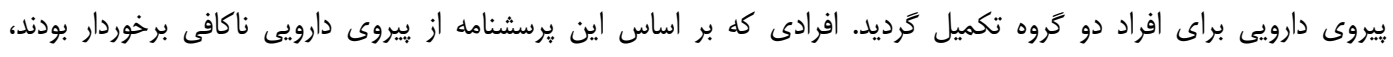

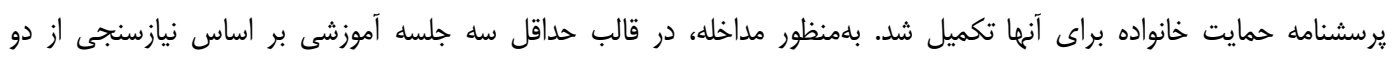

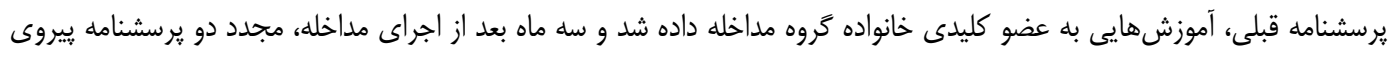

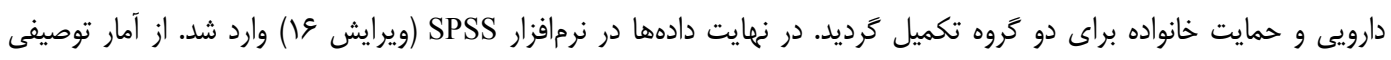

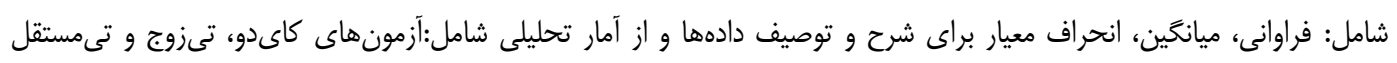

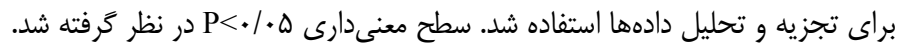

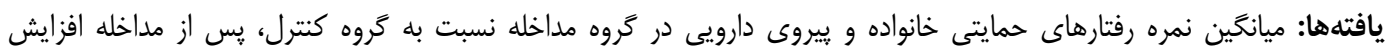

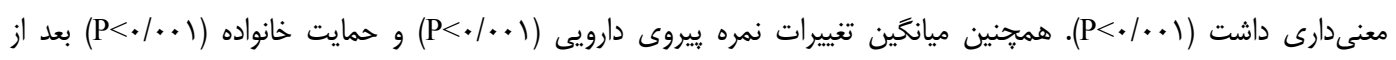

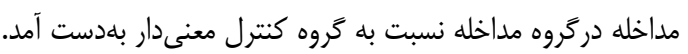
نتيجه كيرى: آموزش رفتارهاى حمايتى خانواده مى تواند سبب بهببود يِيروى دارويى در مبتلايان به انفار كتوس ميوكارد شود. وازههاى كليدى: انفاركتوس ميوكارد؛ يِيروى دارويى؛ حمايت خانوادگى

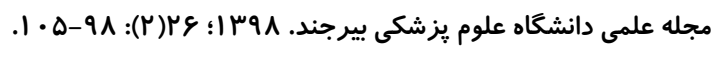
دريافت:

\footnotetext{
' نويسنده مسؤول؛ كميته تحقيقات دانشجويى، دانشكاه علوم يزشكى بيرجند، بيرجند، ايران

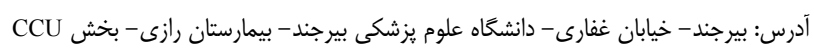

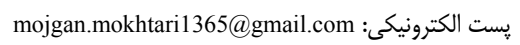

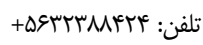

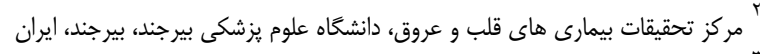

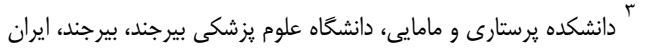


عاطفى، اطلاعاتى و ارزيابى) و حمايتهاى ابزارى (مانند: فعاليتهاى قابل مشاهده كه مىتواند انجام رفتارهاى سالم رانيا

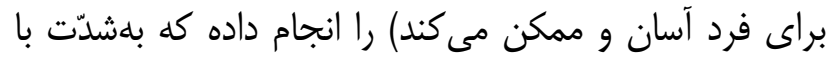
رفتارهاى خودمراقبتى در طول بيمارى مزمن در ارتباط است (T). با توجه به آنجه كفته شد، حمايت اعضاى خانواده مىتواند اثر مثبت يا منفى در بيروى دارويى بيماران

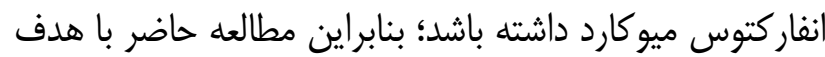

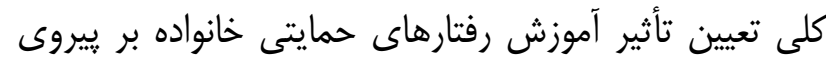

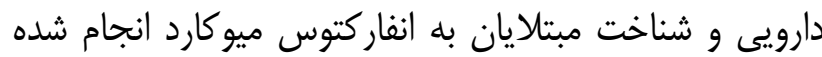

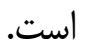

\section{روش تحقيق}

ثزوهش حاضر يك مطالعه كارآزمايى بالينى شاهددار تصادفىشده است. حجم نمونه با استفاده از مطالعه ثنايى و

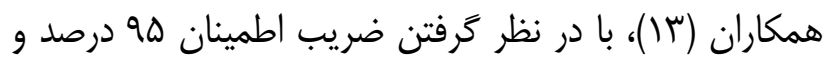

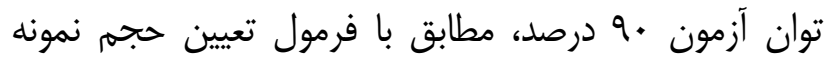

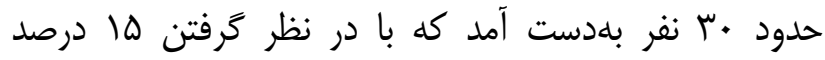

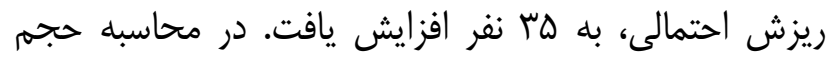

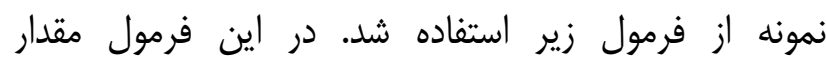

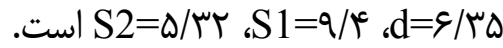

$$
\begin{gathered}
n=\frac{(u+v)^{2}\left(s_{1}+z_{2}\right)^{2}}{\left(\frac{x_{1}-z_{2}}{s}\right)^{2}} \\
\mathrm{n}=\frac{10 / 5\left(9 / 4^{2}+5 / 3^{2}\right)}{\frac{(88 / 66-49 / 96)^{2}}{5 / 3}}=30
\end{gathered}
$$

بدينترتيب • V بيمار مبتلا به انفاركتوس ميوكارد بسترى در بخش CCU' قلب بيمارستان وليعصر (عج) بيرجند در

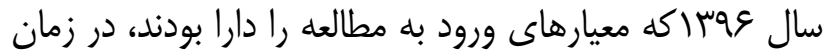
ترخيص به روش نمونه گيرى در دسترس وارد مطالعه شدند و

\footnotetext{
${ }^{1}$ Coronary Care Unit
}

مقلدمه

بيمارىهاى قلبى و عروقى در ايران با اختصاص \&ء

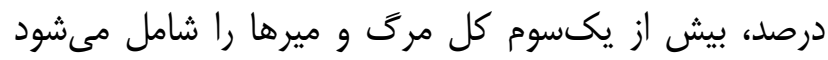

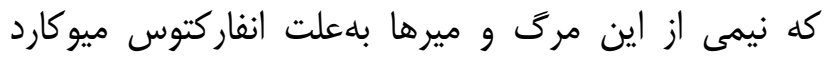

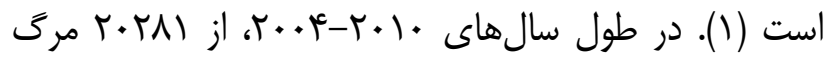
ثبتشده در خراسان جنوبى، بيمارىهاى قلبى و عروقى با

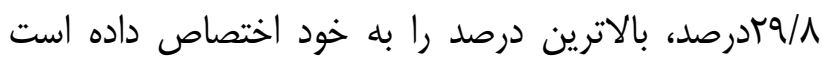

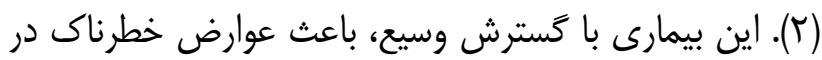

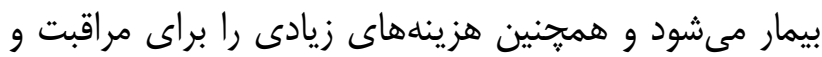

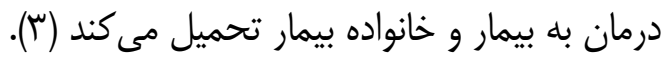

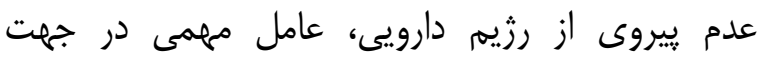
افزايش احتمال بروز عوارض، مرگ و مير، ناتوانى و بالارفتن عندي

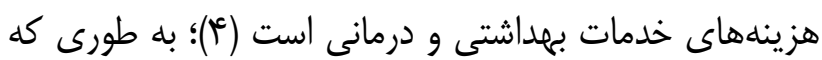

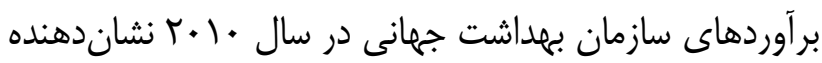

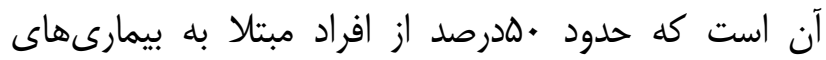
مزمن، داروهاى خود را طبق توصيdها مصرف نمى كنند (ه).

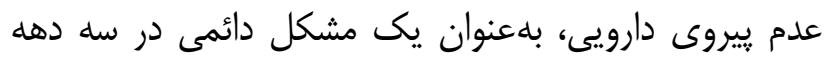
كذشته گزارش شده كه مداخلات فراوان آموزشى، رفتارى و و

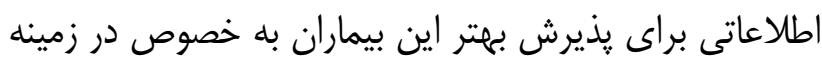

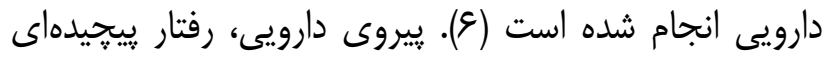

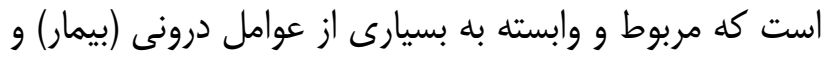

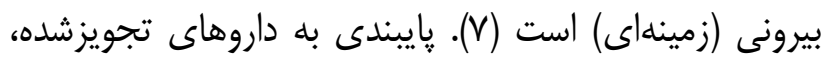

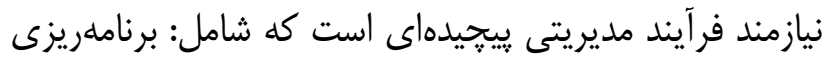

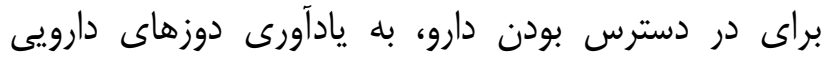

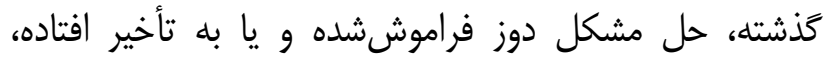
است حدود •ه درصد از افراد مبتلا به بيمارىهاى مزمن كه بايد در طولانىمدت رزيم دارويى خود را مديريت كنند،

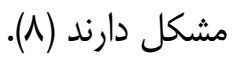
در مطالعات مختلف، ززارش شده است كه حمايت

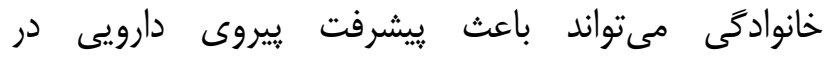

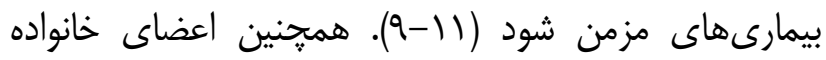
مىتوانند انواع مختلفى از حمايت اجتماعى (مانند: حمايت 


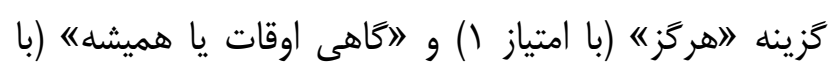

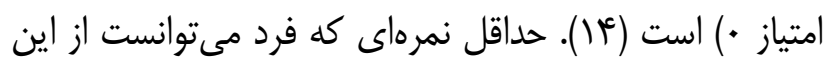

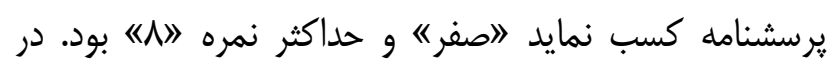

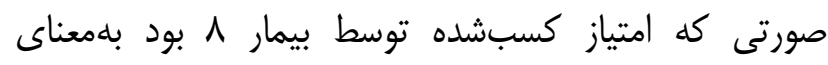

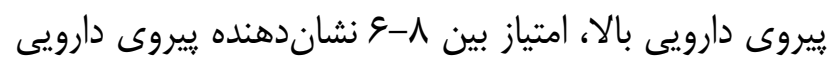

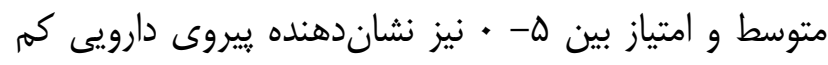

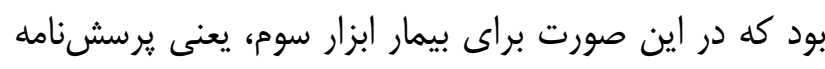

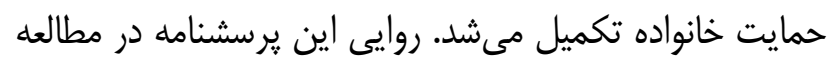

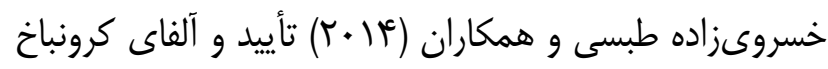

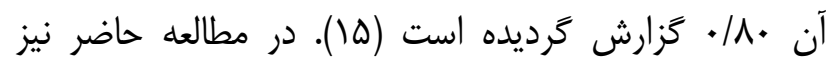
آلفاى كرونباخ براى اين ثرسشنامه / / • • بلهدست آمد.

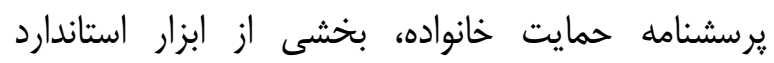

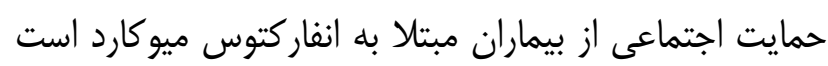

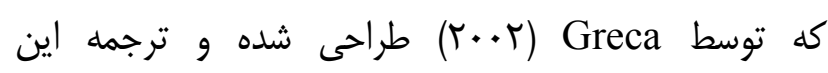

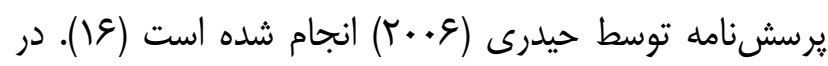

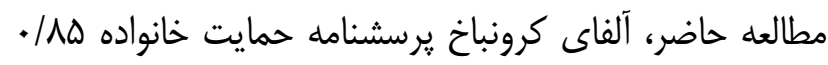

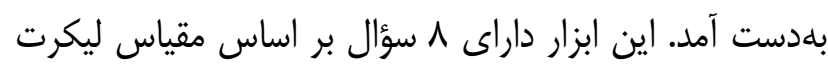

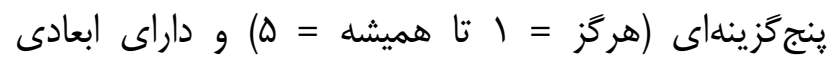

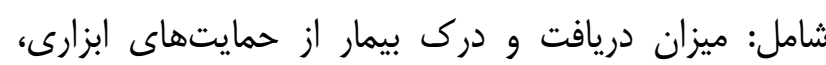

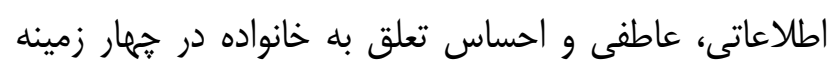

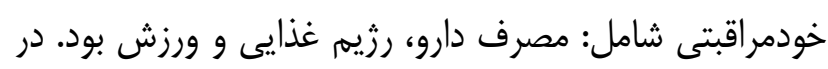

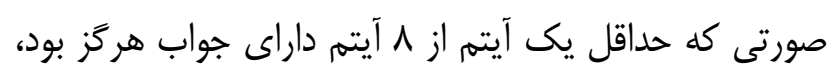

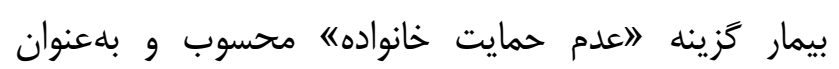
شر كت كننده وارد مطالعه مى كزينه.

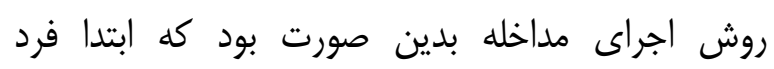

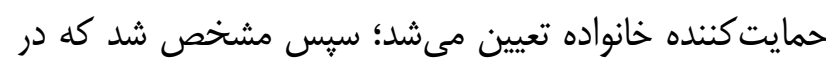

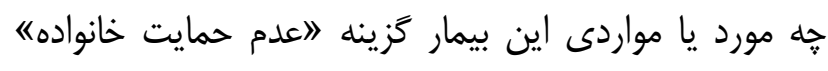

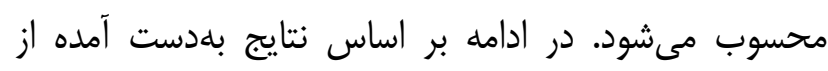

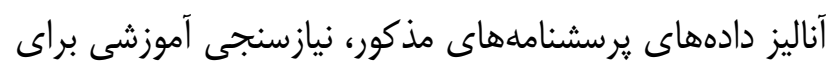

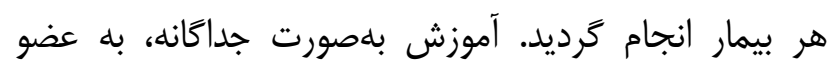

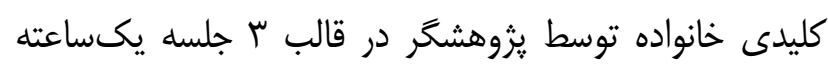

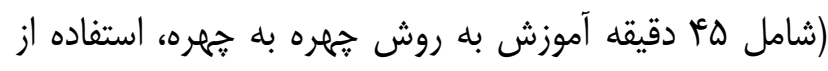

با استفاده از تخصيص تصادفى به روش قرعلهشى، به دو

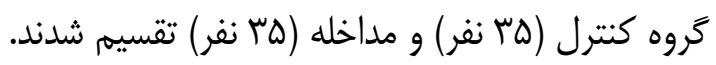

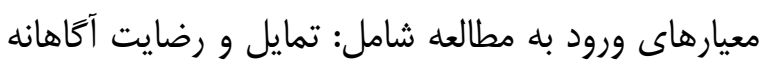
براى حضور در مطالعه، تشخيص قطعى انفاركتوس ميوكارد

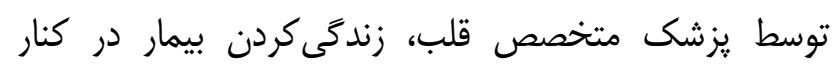

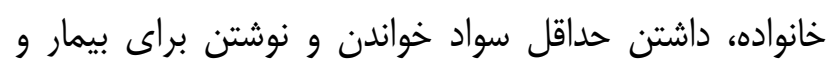

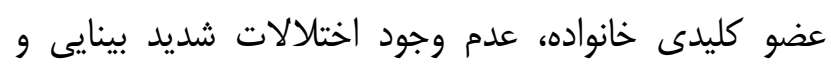

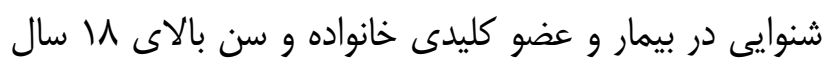
براى عضو كليدى خانواده بود. همجنين افرادى كه شرئ شرايط

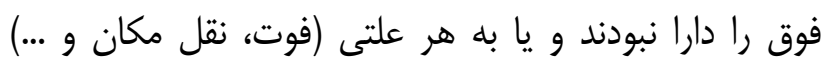
براى ييخيرى بعد از مداخله در دسترس نبودند، از مطالعه كنار

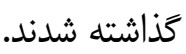
يس از اخذ كد اخلاق (Ir.bums.REC.1395.157) و نيز كد كارآزمايى بالينى (IRCT2017061434535N1)

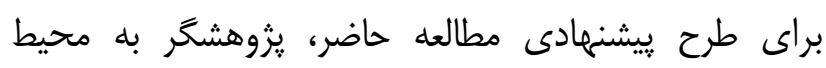

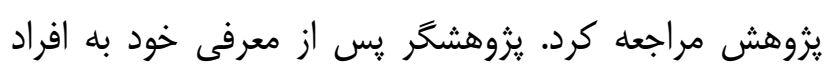

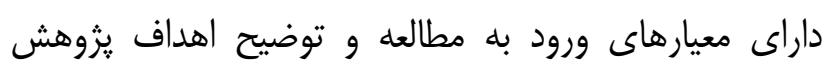

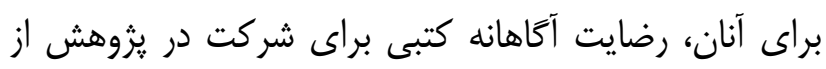

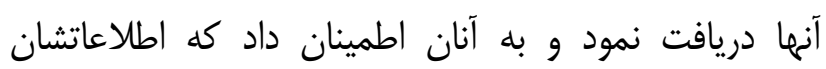
محرمانه باقى خواهد ماند. ابزار زرد آورى دادهها در اين مطالعه يرسشنامه مانده اطلاعات

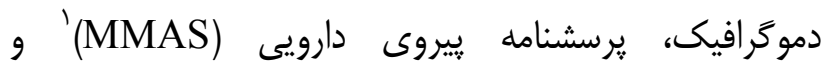

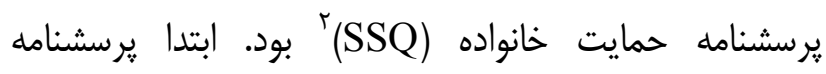

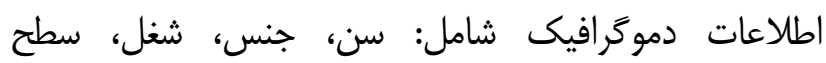
تحصيلات، وضعيت تأهل، تعداد اعضاى خانواده و مراقب داقب

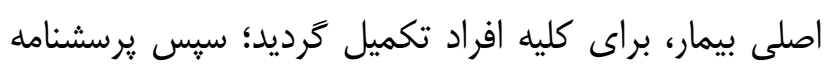
ييروى دارويى MMAS توسط يزوهشگ براى برى كليه بيماران

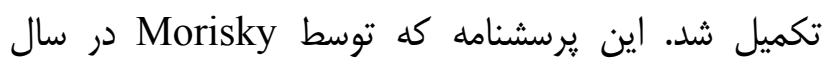

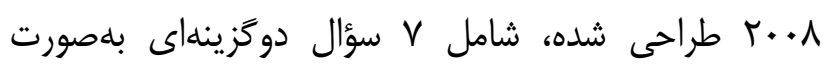

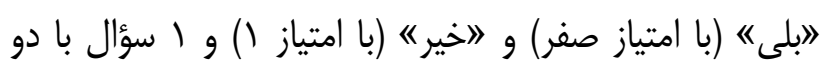

${ }^{1}$ Morisky Medication Adherence Scale

${ }^{2}$ Social support questionnaire-family version 
شركت كنندكان در گروه آزمايش هV

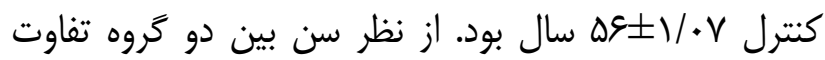

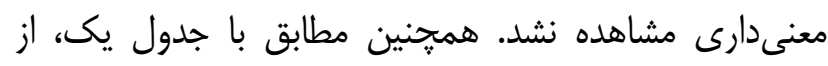

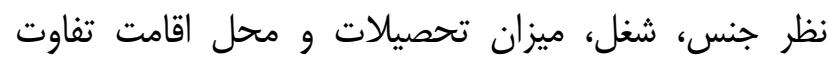

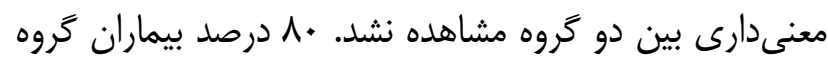

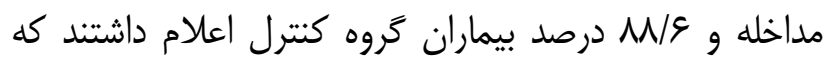
نزديكترين فرد به آنها كه بيشترين حمايت را از ولى ولى دريافت مى كنند، همسرشان است.

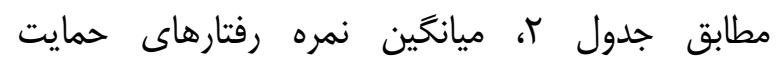
خانوادگى و ييروى دارويى قبل از مداخله در بيماران دو كَروه

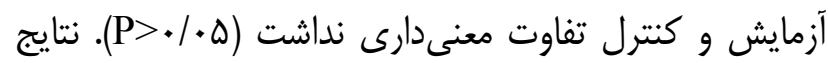

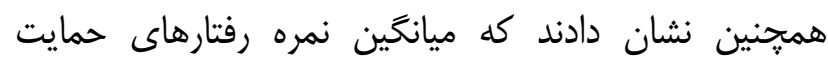

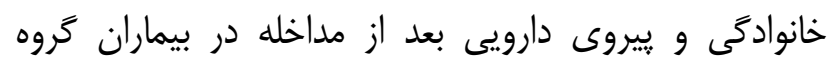

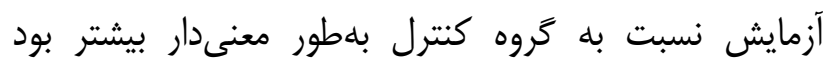

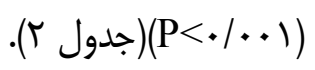

در ادامه نتايج نشان دادند كه ميانخين تغييرات نمره

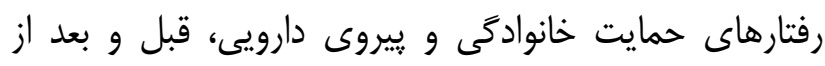

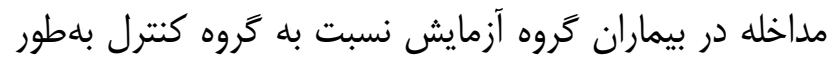

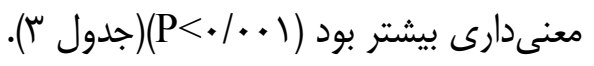

קمفلت و فيلم أموزشى و ها دقيقه يرسش و پاسخ)، روزى يك جلسه انجام مىشد. محل برگزارى اين جلسات كلاس بخش CCU بود. محتواى آموزشى جلسات شامل: ارائه اطلاعاتى در مورد اهميت مصرف داروها، اطلاعاتى در مورد رزيم دارويى (مقدار و زمان مصرف دارو، تداخلات و كنترل

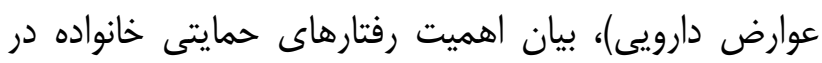

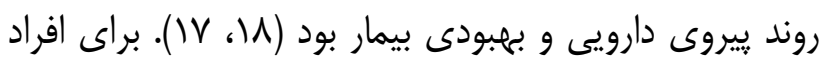

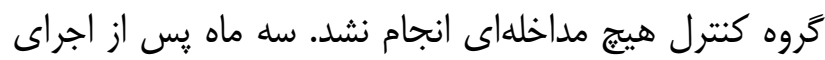

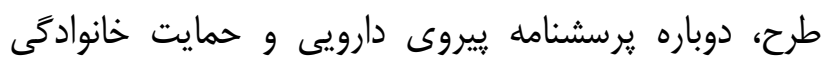
براى افراد هر دو گروه كنترل و مداخله تكميل گرَديد. دادهاى اين يثوهش توسط نرم افزار SPSS عا) و با كمك آمار توصيفى (فراوانى، ميانحَين، انحراف معيار)

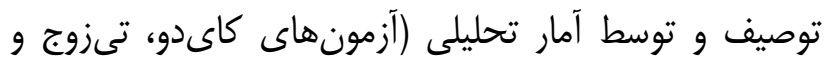

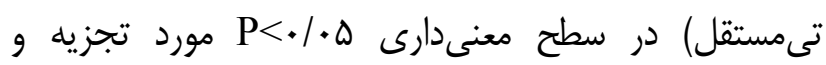
تحليل قرار گرفت.

\section{يافته ها}

در اين مطالعه •V بيمار مبتلا به انفاركتوس ميوكارد

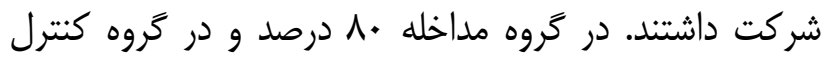

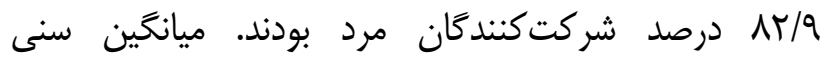
جدول ا - مقايسه توزيع فراوانى مشخصات دموتر افيك شركت كنندكان در مطالعه بر حسب تروه

\begin{tabular}{|c|c|c|c|c|}
\hline $\begin{array}{c}\text { سطح معنى دارى آزمون } \\
\text { كاى (فيشر) }\end{array}$ & 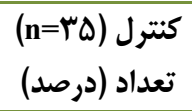 & 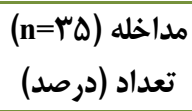 & \multicolumn{2}{|c|}{ متغير } \\
\hline \multirow{2}{*}{$\cdot / v \Delta$} & $(\Lambda \Gamma / 9 \%) r q$ & $(\Lambda \cdot \%) r \Lambda$ & مرد & \multirow{2}{*}{ جنسيّت } \\
\hline & $(I V / 1 \%) \&$ & $(\% \cdot \cdot) v$ & زن & \\
\hline \multirow{4}{*}{ צ } & $(r T / 9 \%) \Lambda$ & $(1 \% / \% \%) \Delta$ & خانه دار & \multirow{4}{*}{ شغل } \\
\hline & $(1 \% / \pi \%) \Delta$ & $(T N / 8 \%) 1$. & كارمندو بازنشسته & \\
\hline & $(r \cdot \%) v$ & $(r \Delta / v \%)^{q}$ & كشاورز & \\
\hline & $(F Y / Q \%) \backslash D$ & $\left.(\mu) / \varphi^{*} \%\right) 11$ & آزاد & \\
\hline \multirow{3}{*}{$\cdot \pi$. } & $(q T / 9 \%) r r$ & $(\Delta \% / \% \%) 19$ & ابتدايى & \multirow{3}{*}{ ميزان تحصيلات } \\
\hline & $(r \Delta / V \%) q$ & $(r \% \%) V$ & راهنمايى و دييرستان & \\
\hline & $(11 / / \% \%))^{c}$ & $(r \Delta / v \%)^{q}$ & دانشخاه & \\
\hline \multirow{2}{*}{ ( ו } & $\left(V I / \kappa^{\circ} \%\right) r \Delta$ & $(\xi * \%) r$ & شهر & \multirow{2}{*}{ محل اقامت } \\
\hline & $($ TN/ধ\%) $)$. & $(f * \%) 1 f$ & ل تروستا & \\
\hline
\end{tabular}


جدول r- مقايسه ميانكَين نمره رفتارهاى حمايت خانوادَّى و بيروى دارويى قبل و بعد از مداخله در بيماران دو تروه

\begin{tabular}{|c|c|c|c|c|}
\hline \multicolumn{3}{|c|}{ زمان } & \multirow{2}{*}{ كروهها } & \multirow{2}{*}{ متغير } \\
\hline سطح معنى دارى & بعد از مداخله & قبل از مداخله & & \\
\hline$<\cdot / \cdot \cdot 1$ & $r N / \mathscr{L} \pm \pm Y / \& V$ & $\mid \varepsilon / \mu \digamma \pm F / \Delta D$ & آزمايش & \\
\hline.$/ T \Delta$ & $|\varepsilon / q \vee \pm r / \wedge|$ & $\mid ه / \wedge q \pm \kappa / \Gamma \Delta$ & كنترل & حمايت خانوادگى \\
\hline & $<\cdot / \cdot \cdot 1$ & $\cdot|\wedge|$ & سطح معنىدارى & \\
\hline$<\cdot / \cdot+1$ & $\Delta / \Delta \mid \pm I / T \Delta$ & $T / I V \pm I / T T$ & آَزْمايش & \\
\hline - & $\begin{array}{c}r / r \cdot \pm 1 / r \cdot \\
<\cdot / \cdot .1\end{array}$ & $\begin{array}{c}r / r \mu \pm 1 / . \cdot \\
. / 9 q\end{array}$ & سطح معنى داري & ييروى دارويى \\
\hline
\end{tabular}

جدول بـ مقايسه ميانكَين تغييرات نمره رفتارهاى حمايت خانوادَّى و ييروى دارويى قبل و بعد از مداخله در بيماران دو تَروه

\begin{tabular}{|c|c|c|c|}
\hline \multirow[b]{2}{*}{ سطح معنىدارى } & \multicolumn{2}{|c|}{ تروه } & \multirow[b]{2}{*}{ متغير } \\
\hline & ميانكين دانحراف معيار & 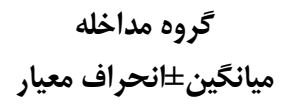 & \\
\hline$<\cdot 1 \cdot \cdot 1$ & $1 / \cdot 9 \pm 4 / M \Lambda$ & $\mid r / \| \pm \pm \Delta / \cdot q$ & حمايت خانوادگى \\
\hline$<\cdot / \cdot \cdot 1$ & $-\cdot / \cdot \mu \pm 1 / r \tau$ & $r / \mu r \pm 1 / \Delta V$ & بيروى دارويى \\
\hline
\end{tabular}

بخشد (·r). يكى از مهرمترين اهداف برنامههاى آموزشى

هدف از انجام اين مطالعه، بررسى ييامد آموزش اجراشده توسط يرستاران، توانمندسازى خانواده در جهت بهان

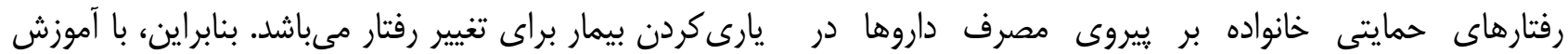

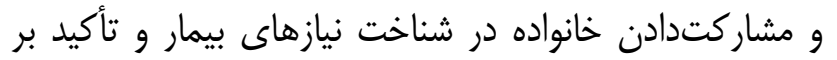
مبتلايان به انفار كتوس ميو كارد بود. نقش كليدى خانواده در كمك به بيمار، مىتوان توانايىهاى نتايج نشان داد كه ميانگين نمره رفتارهاى حمايت خانواده را در حمايت از بيمار ارتقا داد (آT). همجنين، بلددليل خانوادگى بعد از مداخله در گروه آزمايش بلهطور معنىدارى مواجهه مراقبين بيمار با تنشهاى فراوان ناشى از تشخيص افزايش يافت. همجنين ميانخين تغييرات نمره رفتارهاى

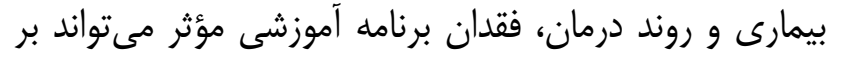
حمايت خانوادگى در بيماران گروه آزمايش نسبت به كروه

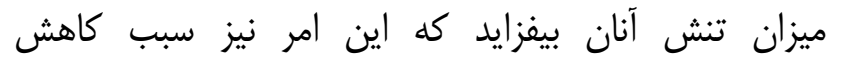
كنترل بلهور معنىدار بيشتر بود. در مطالعهاى به اين نتيجه

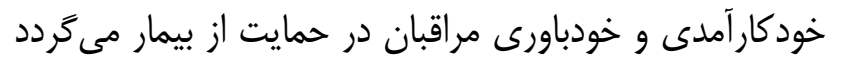
رسيدند كه آموزش به افراد خانواده مىتواند سبب ارتقاى

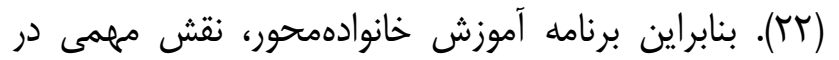
بهبود رفتارهاى حمايتى خانواده از بيمار ايفا مى كند. رفتارهاى حمايتى افراد خانواده از بيمار گردد (ه(). همجنين

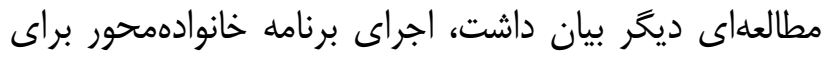
در ادامه، نتايج نشان دادند كه ميانگين نمره يُّيروى مراقبان بيماران مبتلا به نارسايى احتقانى قلب مىتواند سبب دارويى بعد از مداخله در بيماران گروه آزمايش نسبت بهان

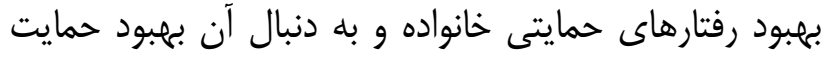
كنترل بلهور معنى دارى بيشتر بهدست أمد. همجنين ميانخين

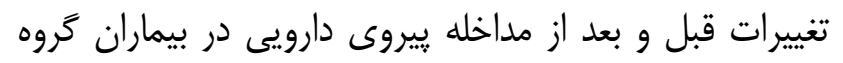

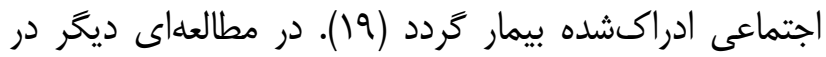

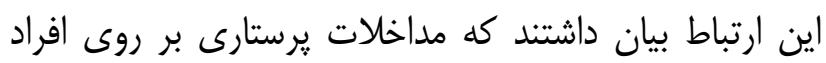

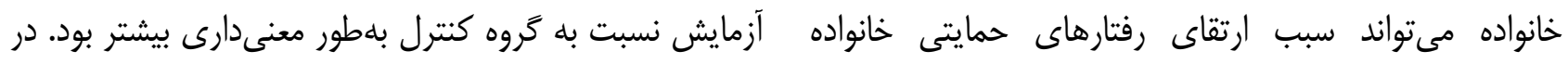

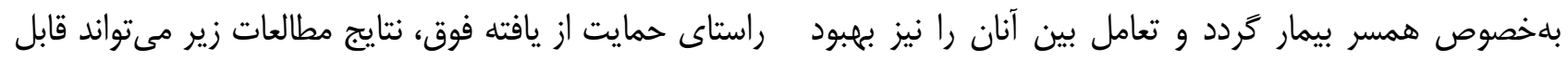


توجه باشد. مطالعه ثنايى و همكاران كه با هدف بررسى تأثير نتيجه كيرى

با توجه به نتايج مطالعه حاضر، آموزش به خانه خانواده

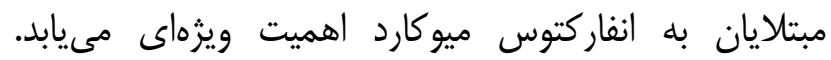

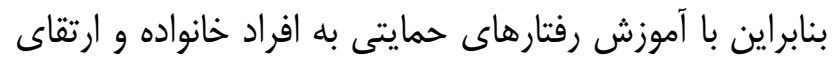

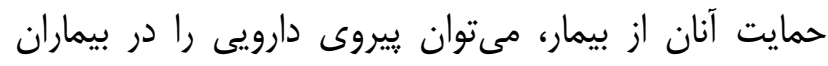

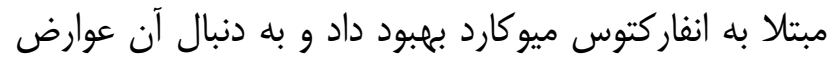

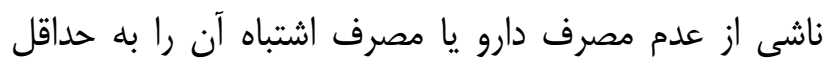
رساند.

\section{تقد ير و تشكر}

از كليه عزيزانى كه به هر نحوى ما را در اجراى اين يثوهش يارى كردند و همجنين يايغاه تحقيقات بالينى

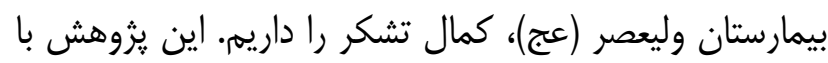

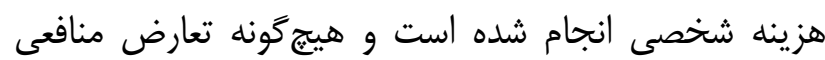

$$
\text { وجود ندارد. }
$$

تضاد منافع : نويسندكان مقاله اعلام مى دارند كه هيجَّونه تضاد منافعى در

$$
\text { يزوهش حاضر وجود ندارد. }
$$

توانمندسازى خانواده محور بر ميزان همكارى خانواده در تبعيت از رزيم درمانى بيماران تحت جراحى باىيس كرونر

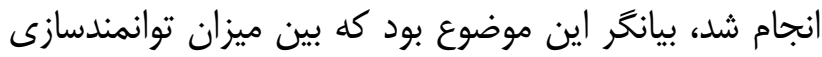

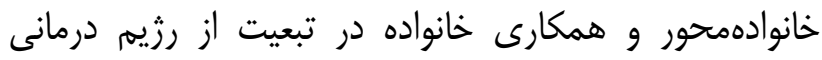

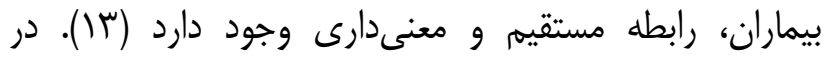

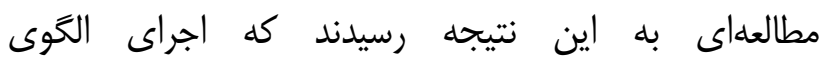

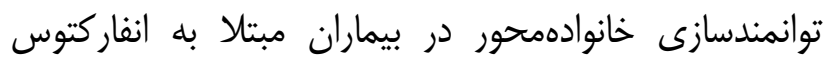

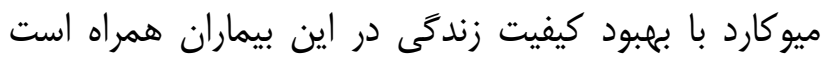

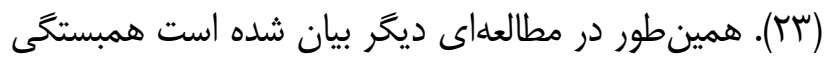

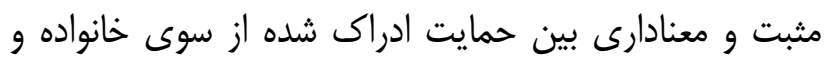

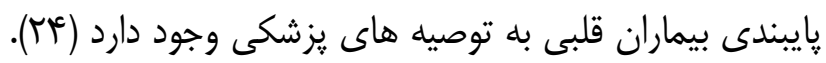

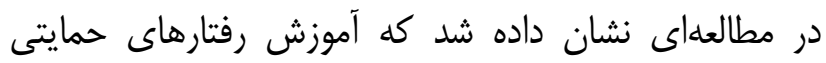

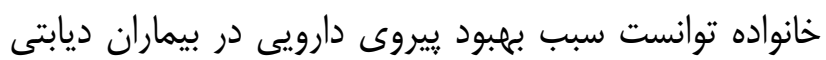

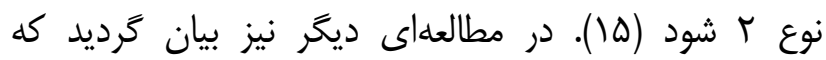

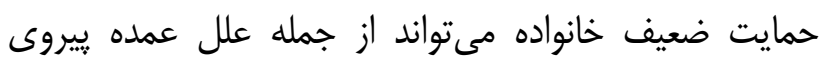

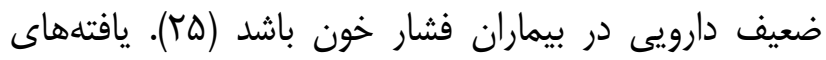

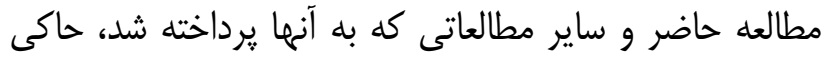

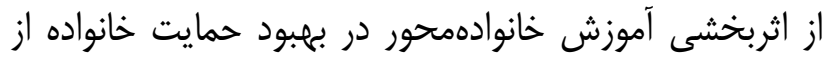
بيمار و تبعيت بهتر بيمار از رزيم دارويى بود. منابع:

1- Koohestani HR, Baghcheghi N, Zand S. Impact of teaching cardiac rehabilitation programs on electrocardiogram changes among patients with myocardial infarction. Iran J Nurs Res. 2010; 5(16): 6-12. [Persian]

2- Kazemi T, Nik M. "World heart day 2014", Significance of cardiovascular diseases in east of Iran. J Res Med Sci. 2015; 20(5): 423. [Persian]

3- Suaya JA, Stason WB, Ades PA, Normand S-LT, Shepard DS. Cardiac rehabilitation and survival in older coronary patients. J Am Coll Cardiol. 2009; 54(1): 25-33. doi: 10.1016/j.jacc.2009.01.078.

4- Hoseini M, Rahmani-Nia F, Samami N, Hoseini R. Relationship of nutrition knowledge and physical activity level with total cholesterol, HDL-C and LDL-C in men with myocardial infarction. Iran J Cardiovasc Nurs J. 2013; 2(3): 2634. [Persian]

5- Cutler DM, Everett W. Thinking outside the pillbox-medication adherence as a priority for health care reform. $\mathrm{N}$ Engl J Med. 2010; 362(17): 1553-5. doi: 10.1056/NEJMp1002305

6- Stilley CS, Bender CM, Dunbar-jacob J, Sereika S, Ryan CM The Impact of Cognitive Function on Medication Management: Three Studies. Health Psychol. 2010; 29(1): 50-55. doi: 10.1037/a0016940

7- Dunbar-Jacob J. Chronic disease: A patient focused view. J Prof Nurs. 2005; 21(1): 3-4. DOI: 10.1016/j.profnurs.2004.12.001 
8- Dunbar-Jacob J, Erlen JA, Schlenk EA, Ryan CM, Sereika S, Doswell WM. Adherence in chronic disease. Annu Rev Nurs Res. 2000; 18: 48-90.

9- Adetunji AA, Ladipo MMA, Irabor AE, Adeleye JO. Perceived family support and blood glucose control in type 2 diabetes. Diabet Int. 2007; 15: 18-9.

10- Mohanan P, Kamath A. Family support for reducing morbidity and mortality in people with HIV/AIDS. Cochrane Database Syst Rev. 2009; (3): CD006046. DOI: 10.1002/14651858.CD006046.pub2.

11- Omosanya OE, Ezeoma IT, Elegbede OT, Agboola SM, Bello IS, Shabi OM, et al. Pattern of family support among HIV patients in a tertiary health centre in southwest Nigeria. Nigerian Journal of Family Practice. 2012; 3(1): 15-9.

12- Mayberry LS, Osborn CY. Family support, medication adherence, and glycemic control among adults with type 2 diabetes. Diabetes care. 2012; 35(6): 1239-45. doi: 10.2337/dc11-2103.

13- Sanaie N, Nejati S, Zolfaghari M, Alhani F, Kazemnezhad A. The effects of family-based empowerment on family cooperation in following patient treatment regime after coroner arteries bypass surgery. Mod Care J. 2014; 11(1): 19-27. [Persian]

14- Morisky DE, Ang A, Krousel-Wood M, Ward HJ. Predictive validity of a medication adherence measure in an outpatient setting. J Clin Hypertens (Greenwich). 2008; 10(5): 348-54.

15- Khosravizade Tabasi H, Madarshahian F, Khoshniat Nikoo M, Hassanabadi M, Mahmoudirad G. Impact of family support improvement behaviors on anti diabetic medication adherence and cognition in type 2 diabetic patients. $\mathrm{J}$ Diabetes Metab Disord. 2014; 13(1): 113. doi: 10.1186/s40200-014-0113-2.

16- Haidari S, Salahshourian A, Rafii F. The relationship between social support and quality of life in cancer patients affiliated to Iran University of Medical Sciences [MSc Dissertation]. Tehran, Iran: Iran University of Medical Sciences; 2006. [Persian]

17- Monajemi A. Health Medical Guide for Cardiovascular Disease. Iran: AzadehMehr publication; 2015. [Persian]

18- Aghdadi A. I want a healthy heart. Iran: Jeihoon publication; 2016. [Persian]

19- Shahriari M, Alimohammadi N, Ahmadi M. Effects of a family centered program on perceived social support in patients with congestive heart failure: An interventional study. J Educ Health Promot. 2016; 5: 6. doi: 10.4103/22779531.184559 .

20- Duhamel F, Dupuis F, Reidy M, Nadon N. A qualitative evaluation of a family nursing intervention. Clin Nurse Spec. 2007; 21(1): 43-9.

21- HoseiniAzizi T, Hasanzadeh F, Esmaily H, Ehsaee M, Masoudynia M. The effect of family's supportive presence on the recovery of patients with brain injury in intensive care unit: a randomized clinical trial. J Urmia Nurs Midwifery Fac. 2014; 11(12): 977-87. [Persian]

22- Jones TM, Hush JM, Dear BF, Titov N, Dean CM. The efficacy of self-management p programmers for increasing p physical activity in community-dwelling adults with acquired brain injury (ABI): A systematic review. Syst Rev. 2014; 3: 39. doi: 10.1186/2046-4053-3-39.

23- Vahedian-Azimi A, Alhani F, Goharimogaddam K, Madani SJ, Naderi A, Hajiesmaeili M. Effect of family-centered empowerment model on the quality of life in patients with myocardial infarction: A clinical trial study. Journal of Nursing Education. 2015; 4(1): 8-22. [Persian]

24- Masoudnia E, Foroozannia Kh, Montazeri M. Relationship between Perceived Social Support and Adherence to Medical Advices among Patients with Coronary Heart Disease after By-pass Surgery. J Shahid Sadoughi Univ Med Sci. 2012; 19(6): 798-806. [Persian]

25- Olowookere AJ, Olowookere SA, Talabi AO, Etonyeaku AC, Adeleke OE, Akinboboye OO. Perceived family support and factors influencing medication adherence among hypertensive patients attending a Nigerian tertiary hospital. Ann Trop Med PH. 2015; 8(6): 241. DOI:10.4103/1755-6783.162668 